ISSN: $1980-055 X$

\title{
AQUECIMENTO GLOBAL E SUAS MANIFESTAÇÕES REGIONAIS E LOCAIS: ALGUNS INDICADORES DA REGIÃO SUL DO BRASIL ${ }^{1}$
}

\author{
Francisco Mendonça²
}

\begin{abstract}
RESUMO
As mudanças climáticas observadas na Era Moderna despertam a atenção de todo o mundo, delineiam o discurso climático-meteorológico-ambiental e se impõem definitivamente na pauta da geopolítica internacional do presente e do futuro. Um consenso internacional, mesmo marcado por algumas vozes dissonante, formado acerca das previsões para a intensificação do aquecimento climático planetário no século XXI aponta para a formação de cenários complicados para os ecossistemas, o meio ambiente e a vida dos homens. No presente texto são evidenciadas características naturais do fenômeno, bem como das interferências decorrentes das atividades humanas na sua intensificação. Alguns reflexos das mudanças climáticas globais na escala regional são evidenciados no presente texto, com destaque para a região Sul do Brasil, na qual foram identificadas alterações térmicas (aquecimento de mais de $0,70 \mathrm{C}$ com mudanças, sobretudo, nas temperaturas mínimas) e elevação dos totais pluviométricos anuais (umidificação com tendência à concentração) nas ultimas décadas.
\end{abstract}

Palavras chave: Clima - mudanças climáticas - aquecimento - Brasil região Sul.

\section{GLOBAL WARMING AND ITS REGIONAL AND LOCALS MANIFES- TATIONS: SOME INDEXES OF BRAZIL'S SOUTHERN REGIONS}

\begin{abstract}
The climatic changes observed in the Modernity attract the attention of everyone. They delineate the climatic-meteorological-environmental speech and they are imposed definitively into the international geopolitical dimension of the present and of the future. An international consensus about that phenomenon, marked as the same time by some dissonant voices, indicates the intensification of the planetary climatic heating in the century XXI appears for the formation of complicated sceneries for the ecosystems, the environment
\end{abstract}

\footnotetext{
${ }^{1} \mathrm{~A}$ abordagem aqui elaborada baseia-se, parcialmente, em resultados obtidos com a elaboração do Projeto de Pesquisa "Dinâmica espacial, monitoramento e controle da dengue na região Sul do Brasil", financiado pelo Ministério da Ciência e Tecnologia/CNPq, Ministério da Saúde/UNESCO e Fundação Araucária de Pesquisa do Paraná.

${ }^{2}$ Doutor em Geografia - Professor Titular UFPR
} 
and the men's life. In the present text natural characteristics of the phenomenon are evidenced, as well as of the current interferences of the human activities on that intensification. Some reflexes of the global climatic changes in the regional scale are evidenced in the present text, with principal regards for the South area of Brazil, in which was identified thermal alterations (heating of more of $0,70 \mathrm{C}$ with changes, above all, in the minimum temperatures) and elevation of the totals annual of rains (with tendency to annual concentration) in the last decades.

Key words: Climate - climate changes - warming - Brazil - South region.

\section{Introdução}

A intensificação do aquecimento global, suas causas e conseqüências têm ganhado cada vez mais importância nos dias atuais. Um cenário de preocupações e inquietações, de dimensão planetária, formou-se nas ultimas décadas em face das possíveis repercussões deste processo em futuro próximo. Ainda que um conjunto representativo de cientistas de todo o mundo tenha se pronunciado publicamente afirmando que as temperaturas médias do planeta aumentaram cerca de $1,5^{\circ} \mathrm{C}$ nos dois últimos séculos, e que ocorrerá uma intensificação da ordem aproximada de $2^{\circ} \mathrm{C}$ a $6^{\circ}$ no século XXI, algumas vozes dissonantes de cientistas que apontam para a ocorrência de um fenômeno contrário a este consenso tem evidenciado a necessidade do aprofundamento do debate acerca das mudanças climáticas globais, sendo este um dos principais propósitos do presente texto.

Assumindo-se que a intensificação do efeito-estufa planetário na Era Moderna é um fato consolidado e consensual admite-se a concepção de que nenhum local do planeta está isento das suas repercussões, pois os fenômenos ligados à natureza são compreendidos à hora atual na escala global e sincronizados com o processo de globalização. A Terra é envolvida por uma única massa gasosa - a atmosfera - que, embora sendo a mesma na China, nos Estados Unidos, na Europa e no Paraná, apresenta particularidades regionais e locais como resultado da interação entre ela e a superfície do planeta. A apropriação diferenciada do espaço geográfico a partir dos territórios modernos (Estados) recortou de tal maneira e com tamanha insensatez a atmosfera (e todos os outros elementos naturais) que despertou a crença, sob o predomínio da concepção estática da mesma, que ela não tivesse a dimensão da interação permanente entre o local e o global, ente o lugar, a nação e o globo. Todavia as principais mudanças climáticas que atiram a atenção da sociedade do presente processam-se na sua camada inferior, particularmente na troposfera, a camada de mistura.

Mudanças climáticas podem ser resultantes naturais do sistema climático, ou ter forte participação antropogênica. As causas de origem antropogênica estão associadas à influência das atividades humanas sobre o meio ambiente, aspecto que se tornou cada vez mais importante conforme a modernidade evoluiu. Das mudanças produzidas ou provocadas pelo homem tem merecido destaque à elevação nos níveis de temperatura média no planeta por conta, 
principalmente, da elevação dos níveis de gases estufa (dentre eles especialmente o gás carbônico e o metano) lançados pelas atividades humanas, os quais vêm mudando a composição e o dinamismo da atmosfera.

Como resultante desse processo de alteração tem-se a elevação da temperatura média da atmosfera da Terra, fenômeno conhecido como intensificação do aquecimento global e que está diretamente associado ao efeito estufa planetário. A região Sul do Brasil está inserida neste contexto global, pois constitui parte deste cenário e participa, portanto, do jogo de causas e conseqüências do processo. A interação entre a dimensão regional e a dimensão global do fenômeno constitui o cerne da análise aqui esboçada.

\section{O Efeito Estufa - Aquecimento Global: Algumas notas}

O efeito estufa é um fenômeno natural que ocorre na baixa atmosfera causado pela retenção de radiação de ondas curtas. Sem ele estima-se que a temperatura média na Terra seria em $33^{\circ} \mathrm{C}$ menor que a atual (Legget, 1992:12), o que o torna essencial para a vida e atividades humanas em diversas áreas do planeta. É assim chamado por atuar de forma semelhante ao que acontece em uma estufa de vidro, porém neste caso a atmosfera atua como o vidro, freando e espaçando o processo de perda da radiação infravermelha emitida pela superfície terrestre. O mais importante efeito-estufa planetário ocorreu após as grandes glaciações no planeta (Plioceno - aproximadamente 12 Milhões de anos atrás) quando a atmosfera da Terra atingiu os cerca de $16^{\circ} \mathrm{C}$ de temperatura média que respondem pela possibilidade da vida humana no planeta; a intensificação deste processo observada na modernidade coloca esta possibilidade em questão, pois o conforto ambiental humano se faz numa muito pequena faixa térmica (entre $16^{\circ} \mathrm{C}$ e $25^{\circ} \mathrm{C}$ ).

A retenção da radiação infravermelha é ocasionada pelos chamados gases estufa. Dentre eles estão, pela ordem de importância e volume na atmosfera, aparecem o vapor d'água, o dióxido de carbono $\left(\mathrm{CO}_{2}\right)$, o metano $\left(\mathrm{CH}_{4}\right)$, o óxido nitroso $\left(\mathrm{N}_{2} \mathrm{O}\right)$ e outros com menor participação, tais como os hidrocarbonetos e compostos artificiais como os clorofluorcarbonos. Estes são gases de longa permanência na atmosfera. O Intergovernamental Panel on Climate Change $(\text { IPCC })^{3}$ acredita que mesmo que se zere totalmente as emissões, o que é inviável, o resultado prático de tal empreitada poderia levar décadas para manifestar seus efeitos sobre o comportamento da atmosfera e do clima.

Uma vez intensificado nas proporções previstas o aquecimento global pode ter sua ação potencializada pelos seus próprios efeitos, a isto se chama retroalimentação. Ela é positiva quando o efeito contribui para aceleração nos processos que o causaram, e negativa quando o efeito acaba por contribuir na redução da causa. Grande parte destes processos se constitui de retroalimentações positivas; um exemplo disso é a elevação nos níveis de vapor d'água na atmosfera causada pela maior evaporação. Como já afirmado anteriormente, o vapor d'água é um dos principais contribuintes para o efeito estufa, sendo que o au-

\footnotetext{
${ }^{3}$ IPCC - Painel Intergovernamental das Mudanças Climáticas. Organismo criado em 1988 pela Assembléia Geral da ONU para tratar das mudanças climáticas globais e que conta com representantes de muitos países do mundo; o Brasil tem sido ali representado principalmente por cientistas ligados ao INPE - Instituto Nacional de Pesquisas Espaciais.
} 
mento em seus níveis contribuirá para potencializar o efeito estufa.

Poucos fenômenos de retroalimentação negativa foram identificados. Os mais conhecidos são a possibilidade de melhoria na fotossíntese, e o maior crescimento das plantas, promovida pela maior concentração de $\mathrm{CO}_{2}$ na atmosfera. Com isso as florestas teriam aumentadas sua biomassa, o que acabaria por retirar mais dióxido de carbono da atmosfera (Legget:1992:32). Entretanto o que se sabe sobre retroalimentações encontra-se ainda, sobretudo, no campo hipotético, sendo seus impactos ainda bastante incertos.

\subsection{Causas da intensificação do aquecimento global}

A tônica proeminente nos mais diversos eventos científicos das últimas décadas é relativa à elevação da concentração, e conseqüente alteração no equilíbrio natural, dos gases de aquecimento da atmosfera. Acredita-se que o principal responsável por essas alterações seja o homem, pois a atividade industrial mudou a base energética e intensificou o consumo de combustíveis fósseis; em princípio o carvão mineral (fase inicial e mediana da era industrial) e posteriormente o petróleo (fase mediana e avançada da era industrial).

A queima desses combustíveis lança na atmosfera grandes quantidades de $\mathrm{CO}_{2}$, contribuindo para o aumento de sua concentração na atmosfera e, portanto, para a retenção de mais calor na troposfera. Simultaneamente os clorofuorcarbonos - CFCS - atuam na degradação do ozônio $\left(\mathrm{O}_{3}\right)$ troposférico-estratosférico, o que resulta na passagem de mais raios caloríficos (ultravioleta) para a baixa atmosfera, que são então aprisionados resultando na intensificação do aquecimento global.

O consumo de carvão mineral que, no século XIX era de 15 milhões de toneladas, passou a 132 milhões de toneladas em 1860, atingindo no final do século XIX 700 milhões de toneladas. Contudo, no século XX o carvão perde importância ante a expansão no consumo de derivados de petróleo. É possível perceber claramente o aumento do consumo do petróleo comparando-se os números de sua produção: em 1890 era de 10 milhões de toneladas, atingindo 2.286 milhões de toneladas na década de 70. A queima destes combustíveis (Estados Unidos, Europa, Japão e países industrializados estão dentre aqueles donde as emissões são as mais importantes) vem liberando para a atmosfera grande volume do carbono aprisionado na superfície do planeta ao longo de eras geológicas.

Outras atividades humanas que interferem nos biomas terrestres são também consideradas causas da intensificação do aquecimento global; dentre elas destacam-se: o desmatamento, que pode causar aumento da carga de $\mathrm{CO}_{2}$ na atmosfera, seja pela redução da fotossíntese ou pela queima de material vegetal oriunda das florestas derrubadas (Brasil encontra-se dentre um dos principais contribuintes nas emissões derivadas desta atividade); a rizicultura irrigada - que produz grandes quantidades de gás metano, e a pecuária - que contribui com o lançamento de dióxido de carbono e de metano, este também produzido no processo de produção - consumo - geração de resíduos sólidos na sociedade contemporânea.

Segundo o IPCC, desde 1750 a concentração de $\mathrm{CO}_{2}$ na atmosfera aumentou em $31 \%$, a de $\mathrm{CH}_{4}$ em $151 \%$ e a de $\mathrm{N}_{2} \mathrm{O}$ em $17 \%$. O aumento na con- 
centração destes gases contribuiu para a elevação de $0,6^{\circ} \mathrm{C}$ a $2,0^{\circ} \mathrm{C}$ na temperatura média do ar na superfície do planeta somente no século XX. O mesmo estudo do IPCC apontou a década de 1990 como sendo a mais quente desde 1861 .

\subsection{Efeitos da intensificação do aquecimento global}

Prognósticos recentes do IPCC têm apontado para um aumento da ordem de 1,4 (otimista) a $5,8^{\circ} \mathrm{C}$ (pessimista) nas médias térmicas globais para período de 1990 a 2100 . Como conseqüência desta elevação estão previstos aumentos nos índices de precipitação, principalmente nas latitudes médias e altas, ao mesmo tempo em que haverá redução nos níveis pluviométricos nas baixas latitudes (Mendonça, 2004).

Os mesmos modelos climáticos que apontaram para estas previsões também indicaram a possibilidade de redução do gelo Ártico pelo derretimento, enquanto a Antártica pode passar a aumentar sua massa de gelo pelo aumento das precipitações, embora haja controvérsias quanto a esta ultima região; de toda maneira estima-se que haverá importante degelo dos glaciares que cobrem parte dos continentes.

Alguns cenários têm apontado para uma elevação do nível médio dos mares na ordem de 0,09 (otimistas) a 2,00 metros (pessimistas) entre 1990 e 2100 , decorrente tanto do derretimento de parte das calotas polares e das geleiras continentais, quanto pela expansão térmica provocada pela elevação média da temperatura terrestre. $O$ incremento de águas doces e de menores temperaturas proveniente do desgelo destas superfícies provocaria alterações no fluxo das correntes marinhas que, indiretamente, provocaria alterações substanciais na configuração climática do planeta; o mais midiático destes fenômenos tem sido as modelizações acerca do recuo e retenção das correntes marinhas quentes, como a Gulf Stream, em latitudes mais baixas.

As variações na precipitação e na evapotranspiração atuarão sobre a distribuição de água no planeta de forma diferenciada. Algumas regiões terão incrementados seus volumes de água e assim intensificados fenômenos como chuvas torrenciais seguidas por enchentes, deslizamentos, movimentos de massa e erosão do solo. Os sedimentos provenientes do aumento do potencial erosivo, por exemplo, poderão comprometer os depósitos de água potável, ao passo que em outras regiões ocorrerá redução no regime de chuvas tornando o solo árido, inviabilizando determinadas atividades agrícolas, etc.

$\mathrm{Na}$ agricultura o aumento de $\mathrm{CO}_{2}$ poderá contribuir, em princípio, para o crescimento de plantas; contudo as variações nos regimes de chuva e temperatura exigirão alterações nos sistemas de irrigação, adubação, seleção de culturas e controle de pragas. Altos investimentos serão exigidos, trazendo dificuldades principalmente para o pequeno produtor. As mudanças climáticas promoverão mudanças na distribuição espacial das culturas, algumas não serão mais viáveis em certas regiões.

Os sistemas biológicos também serão afetados. Segundo o IPCC a migração de biomas ou ecossistemas pode ser discreta, refletindo-se em mudanças na composição do conjunto de espécies ou surgimento de novas espécies dominantes em determinadas áreas. Estas mudanças podem ocorrer ao longo de 
décadas ou séculos e causar um empobrecimento em vários ecossistemas. Um exemplo disto no Brasil é a possibilidade de recuo nas áreas cobertas por florestas de Araucárias, que tem sua espacialização diretamente influenciada pelo clima. Confirmadas as elevações nas médias de temperaturas previstas haverá, em longo prazo, uma redução das áreas de cobertura de Araucárias e uma expansão de ecossistemas florestados tropicais sobre estas áreas.

Algumas populações podem ser expulsas de suas regiões de origem sendo obrigadas a migrar, em busca de terras, alimentos e água potável, para novas regiões, donde se falar de migrações forçadas e do exílio ambiental. Woodwell (1992) classificou de "refugiados ambientais" as populações humanas que, suscetíveis aos efeitos da mudança do ambiente, migram em busca de melhores condições. A luta pela sobrevivência exigirá dos mais pobres esforços redobrados, fato que explicita o acirramento das injustiças sociais decorrentes das mudanças globais, o que incidirá diretamente no desenvolvimento de sérios e intensos conflitos socioambientais.

Os sistemas marinhos serão diretamente afetados. O aumento do nível do mar provocará inundações em zonas costeiras atingindo cidades litorâneas, manguezais, etc. Alguns muito pequenos países insulares do Oceano Pacífico poderão ser submersos, e haverá contaminação em aqüíferos de água potável das planícies litorâneas pela água salgada que ingressará nos complexos estuarinos. No Brasil a situação é preocupante, pois desde a colonização, o maior contingente populacional brasileiro habita em regiões costeiras, que serão afetadas diretamente pelas mudanças.

O aumento nas médias térmicas e a conseqüente elevação das precipitações podem intensificar a disseminação de vetores de doenças como a malária, a dengue, a cólera, a esquistossomose, a leishmaniose e a encefalite japonesa, além dos problemas causados pela desnutrição oriunda da carência alimentar, casos de diarréias, de desidratação e afogamentos (Mendonça, 2033, 2004 e 2006). As ondas de calor farão aumentar a umidade e a poluição, principalmente nos grandes centros urbanos, agravando os problemas respiratórios da população.

Sem condições de habitações dignas, e com falhas de nutrição causadas pela péssima alimentação, serão as populações pobres, principalmente nos grandes aglomerados populacionais, as mais atingidas. Agrupamentos humanos distintos sofrerão conseqüências diferenciadas, pois a capacidade de adaptação humana é bastante diversificada. Neste sentido, e em função da concentração do poder econômico, político, científico e tecnológico estima-se que as populações dos países desenvolvidos sofrerão menos os efeitos da intensificação do aquecimento se comparada àquela dos países subdesenvolvidos, que possuem limitada capacidade de adaptação, mesmo em considerando-se que as principais alterações climáticas processar-se-ão sobre aqueles.

Os efeitos do aquecimento global não atingirão de forma homogênea à todas as regiões do planeta. Pela própria complexidade dos sistemas terrestres algumas áreas são particularmente mais vulneráveis que outras. Mesmo sabendo-se que os principais efeitos das mudanças climáticas globais ocorrerão nas regiões de latitudes médias e altas, os mais graves problemas não serão, necessariamente, registrados nelas. Apesar dos predominantes cenários catastrofístas apresentados por cientistas e veiculados enfaticamente pela mídia internacional, 
há que se assinalar que efeitos positivos também serão observados como decorrentes das mudanças climáticas anunciadas, dentre eles cita-se a expansão de áreas agrícolas com características tropicais - subtropicais, a redução das doenças ligadas a baixas temperaturas, etc. $\mathrm{O}$ aspecto mais preocupante ligado a este tipo de ação da mídia liga-se à aceitação e aprovação apressadas, por parte de governos e da população em geral, de processos apresentados como freadores ou inibidores da intensificação do efeito-estufa sem uma reflexão mais profunda, como é o caso da "revolução dos biocombustíveis" ${ }^{4}$ e da energia nuclear nos dias atuais.

\subsection{Os fóruns internacionais de debates: A dimensão política das mudanças climáticas globais}

Na década de 1970 começaram a vir à tona, de forma mais enfática, as questões ambientais. Em 1972 a Organização das Nações Unidas - ONU promoveu a I Conferência sobre Meio Ambiente, realizada em Estocolmo na Suécia, cujo principal produto foi a Declaração de Estocolmo, posteriormente complementada pela Declaração de Cocoyoc (1974) que estabeleceu o conceito de ecodesenvolvimento, mais tarde transformado em desenvolvimento sustentável (Sachs, 1993).

A segunda conferência mundial sobre o meio ambiente foi realizada no Rio de Janeiro em 1992 (Eco-92). Nesta conferência já se incluiu em sua denominação o termo desenvolvimento, sendo oficialmente denominada II Conferência das Nações Unidas sobre o Meio Ambiente e Desenvolvimento (II CNUMAD), cujo principal objetivo foi o de obter, através de negociações, a redução na concentração de gases estufa na atmosfera limitando a interferência antropogênica nos sistemas climáticos.

A questão reveste-se, na atualidade, de uma forte conotação política (Mendonça et alli, 2001) e deve ser tratada com a seriedade inerente de processos com efeitos profundos sobre o porvir da humanidade. Neste sentido Mendonça (1992) evidenciou algumas propostas visando à mitigação das mudanças climáticas, tais como: engajamento de governos; programas de educação ambiental e recuperação de áreas degradadas; alteração nas formas de produção e consumo; políticas que evitem o desmatamento; redução das migrações campo-cidade; mudança do padrão energético, entre outras.

Além dos avanços conceituais observados durante a Eco-92, constata-se que houve progresso na conscientização dos governos dos inúmeros países participantes; o resultado prático foi a criação de agencias de meio ambiente na maioria dos países e a Agenda-21.

\footnotetext{
${ }^{4}$ O Brasil foi apontado, recentemente, como uma potencia energética do futuro a partir da produção e consumo do álcool. Este "biocombustível" é tomado, de maneira genérica, como uma energia limpa devido a emitir menos poluição e gases de aquecimento para a atmosfera no processo de sua queima em automóveis. Todavia, não estão sendo questionados os problemas ligados ao processo de produção do álcool, tais como a queima da cana antes da usinagem, a poluição ambiental generalizada no entorno das usinas, do solo e dos cursos hídricos, nem tampouco as complexas condições de trabalho - injustiça social - que marcam o processo.
}

${ }^{5}$ Muito recentemente alguns periódicos têm tratado da energia nuclear como uma energia limpa devido à sua não emissão de gases de efeito-estufa ! 
A pauta da Eco-92 baseou-se nos princípios das responsabilidades diferenciadas; na prática isso significa que o país mais industrializado, por poluírem mais, tem maiores obrigações sobre a manutenção do meio ambiente terrestre, pois $20 \%$ da população mundial vivem em países industrializados que respondem por $80 \%$ da descarga de gases estufa na atmosfera (Global Equity \& Climate Change, 1999). O governo dos Estados Unidos, por exemplo, não aceitou o estabelecimento de responsabilidades diferenciadas, pois, por serem os maiores emissores de gases estufa no planeta (33\%), seriam os mais prejudicados economicamente; estima-se que o custo da redução de emissão para cada país será da ordem de $1,3 \%$ do produto interno bruto, o que no Brasil giraria em torno de US\$10 bilhões de dólares anuais (Novaes, 2000).

$\mathrm{Na}$ sua proposta o governo dos Estados Unidos posicionou-se pela distribuição equânime de obrigações entre as nações, isto é, o percentual de redução na emissão deveria ser igual para todos os países. No relatório final a proposta americana foi rejeitada, prevalecendo a idéia de responsabilidades diferenciadas. Se aprovada haveria obrigações iguais para todos os países, independente dos níveis de industrialização de cada um, acarretando uma dificuldade maior para os países pobres que teriam seu desenvolvimento tolhido pelo percentual de redução de emissões a que seriam obrigados a respeitar (Globe, 1999).

O principal produto da II CNUMAD foi a elaboração da Agenda 21. Nela estão estabelecidas as recomendações práticas para viabilizar o desenvolvimento econômico sem prejuízo ao meio ambiente, seguindo a idéia de desenvolvimento sustentável. A agenda considerou as diferenças regionais, tratando de questões como a pobreza no mundo e as desigualdades econômicas-sociais entre os países do hemisfério Norte e os do Sul. A abrangência da Agenda 21 é grande e cada estado ou município deve ter a sua, possibilitando priorizar ações em níveis federal, estadual e municipal, considerando-se as diferenças locais. Cerca de mais de 100 nações acataram as decisões da Eco-92, inclusive os países da União Européia; como resultado prático da Eco-92 houve uma conscientização da importância da redução na emissão de gases estufa, passando a ser mais freqüente as conferências para tratar do tema.

Na Primeira Conferência das Partes - COP1, realizada em abril de 1995 na cidade de Berlim, foi dada continuidade às discussões iniciadas no Rio de Janeiro. Seu principal objetivo era finalizar as negociações para um acordo internacional, com metas bem definidas de emissão de gases estufa; em 1996 a conferencia foi realizada na cidade de Genebra (Suíça) e, em 1997, na cidade de Kyoto (Japão) na qual deliberou-se pelo Protocolo de Kyoto.

Nesta conferencia os países mais industrializados (Estados Unidos, Comunidade Européia, Rússia, Japão entre outros) concordaram com a estabilização das emissões, porém afirmaram ser possível atingir o nível das emissões de 1990 somente entre os anos de 2010 e 2015; comprometeram-se a atingir uma cota de emissão 5,2\% menor do que a de 1990. Em Kyoto o mundo foi dividido em dois grupos, os chamados países do Anexo 1 ou industrializados, e os não-Anexo 1, que são os países em níveis de industrialização intermediários e com expressiva liderança regional (Grupo dos 77$)^{6}$, dentre os quais o Brasil teve papel destacado. O país apresentou a proposta que culminou no MDL - Mecanis-

${ }^{6}$ Coalizão de países de Terceiro Mundo estabelecida em 1964 com o objetivo de prover o desenvolvimento econômico e de cooperação técnica. 
mo de Desenvolvimento Limpo, através do qual os países industrializados investem em projetos ligados ao meio ambiente em países não industrializados, em troca de um abono considerado como redução líquida de sua emissão... Enfim, o "mercado de cotas" foi criado.

Outras conferencias foram seqüencialmente realizadas no sentido de avançar num melhor conhecimento das mudanças climáticas, bem como na política que permeia as responsabilidades dos diferentes países no que concerne à intensificação do processo. Mesmo que as discussões tenham sido lentas, emperradas pelas burocracias e pressionadas por questões econômicas, há muito de positivo nos resultados obtidos nesta última década. O principal deles talvez seja a conscientização generalizada quanto aos danos causados ao meio ambiente. Todavia, mesmo com o processo de conscientização em curso o mais difícil parece ser a elaboração e a implementação de planos para uma efetiva estabilização e redução das agressões humanas à atmosfera.

O Brasil tem se destacado na busca de alternativas energéticas limpas, não só pela grande capacidade de geração de energia elétrica da rede hidrográfica brasileira, mas também pelo desenvolvimento de soluções alternativas como o programa pró-álcool, entre outras. Há claramente uma redução percentual no consumo de combustíveis de carbono, tais como o petróleo e a madeira; enquanto fontes mais limpas como a energia elétrica e os produtos da cana de açúcar, energias "mais limpas", percentualmente cresceram em consumo. O Brasil tem uma participação nas emissões de gases estufa na ordem de $4 \%$, provenientes principalmente do desmatamento, considerado como um valor modesto pela extensão territorial do país; no entanto, deste valor estão excluídos os índices relativos às queimadas, devido à sua difícil quantificação.

Os avanços no campo legal e a crescente utilização de energias limpas mostram que o Brasil tem desempenhado com responsabilidade seu papel perante os compromissos internacionais, embora muito ainda há que se fazer. Os problemas nacionais são enormes, das queimadas à redução da área da floresta amazônica, passando pelos problemas ambientais urbanos e industriais. Apesar de sua legislação ambiental ser boa qualidade, o país ainda apresenta sérias deficiências no cuidado com o meio ambiente. Isto é agravado pela falta de fiscalização não só pelo Estado, mas também pelo baixo engajamento da sociedade civil, e pela excessiva concentração de renda em muito pequena parcela da população, o que se repercute numa inaceitável pobreza e miserabilidade social.

\section{Região Sul: Evolução e tendências climáticas recentes}

Analisando-se os dados meteorológicos de inúmeras localidades na região Sul do Brasil (figura 1 ) pode-se constatar uma tendência à elevação das temperaturas em toda a região. Em termos gerais estima-se que nos últimos quarenta anos a temperatura média regional elevou-se cerca de $1,3^{\circ} \mathrm{C}$, o que teria sido acompanhado por uma elevação dos totais pluviométricos médios anuais. 


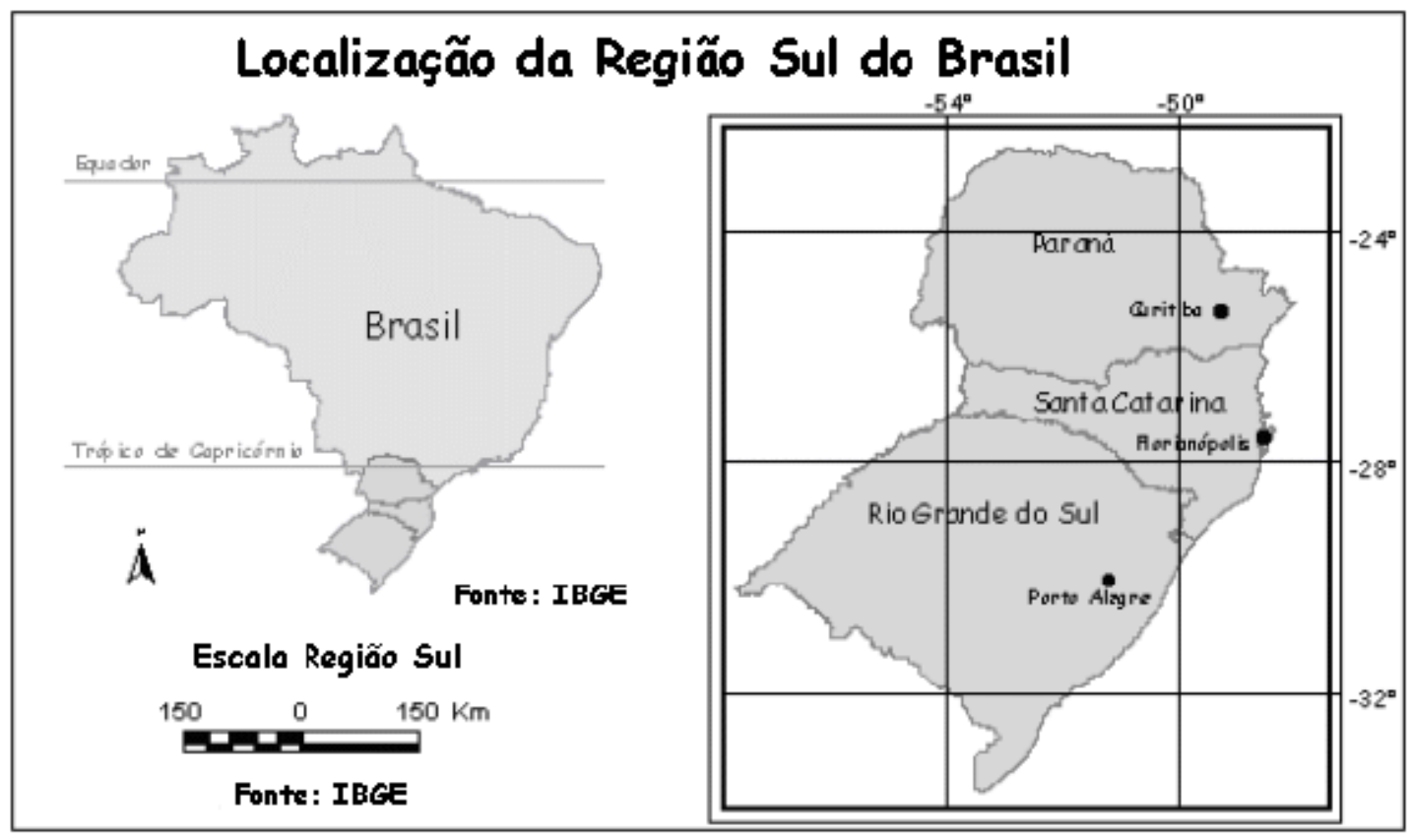

Figura 1. Região Sul do Brasil.

Para ilustrar este cenário regional, que responde de maneira exemplar as perspectivas globais divulgadas pelo IPCC, analisou-se uma base de dados meteorológicos regionais fornecida por algumas instituições meteorológicas da região tais como INMET (Instituto Nacional de Meteorologia), IAPAR (Instituto Agronômico do Paraná), EPAGRI (Empresa de Pesquisa Agropecuária de Santa Catarina) e FEPAGRO (Fundação de Pesquisa Agropecuária do Rio Grande do Sul) para o período 1961 - 2004. Os dados foram tratados estatisticamente através de tendência linear e de tendência polinomial; o primeiro exercício revelou tendência linear à elevação em cerca de $90 \%$ das localidades, fato que reflete a tendência geral de aquecimento da atmosfera do planeta na escala regional.

A tabela 1 , referente à evolução e tendências térmicas lineares da região Sul do país, evidencia a intensificação do aquecimento no âmbito regional (período de analise 1961-2004). Os dados de cerca de 38 localidades (08 no Estado do Paraná, 07 no Estado de Santa Catarina e 23 no Estado do Rio Grande do Sul) foram tratados e analisados, sendo que revelaram tendência a aquecimento na maioria delas (em 26 das 38). A intensificação do aquecimento regional, todavia, evidencia-se diferentemente tanto espacial quanto no comportamento térmico.

A principal alteração observada traduz-se na elevação das temperaturas médias das mínimas (figura 2), seqüenciada pelas temperaturas médias compensadas (figura 3) e, posteriormente, pelas temperaturas médias das máximas (figura 4). 
Revista Brasileira de Climatologia, Vol. 2, p. 71-86.

Tabela 1. Evolução e tendências térmicas lineares da região Sul do Brasil.

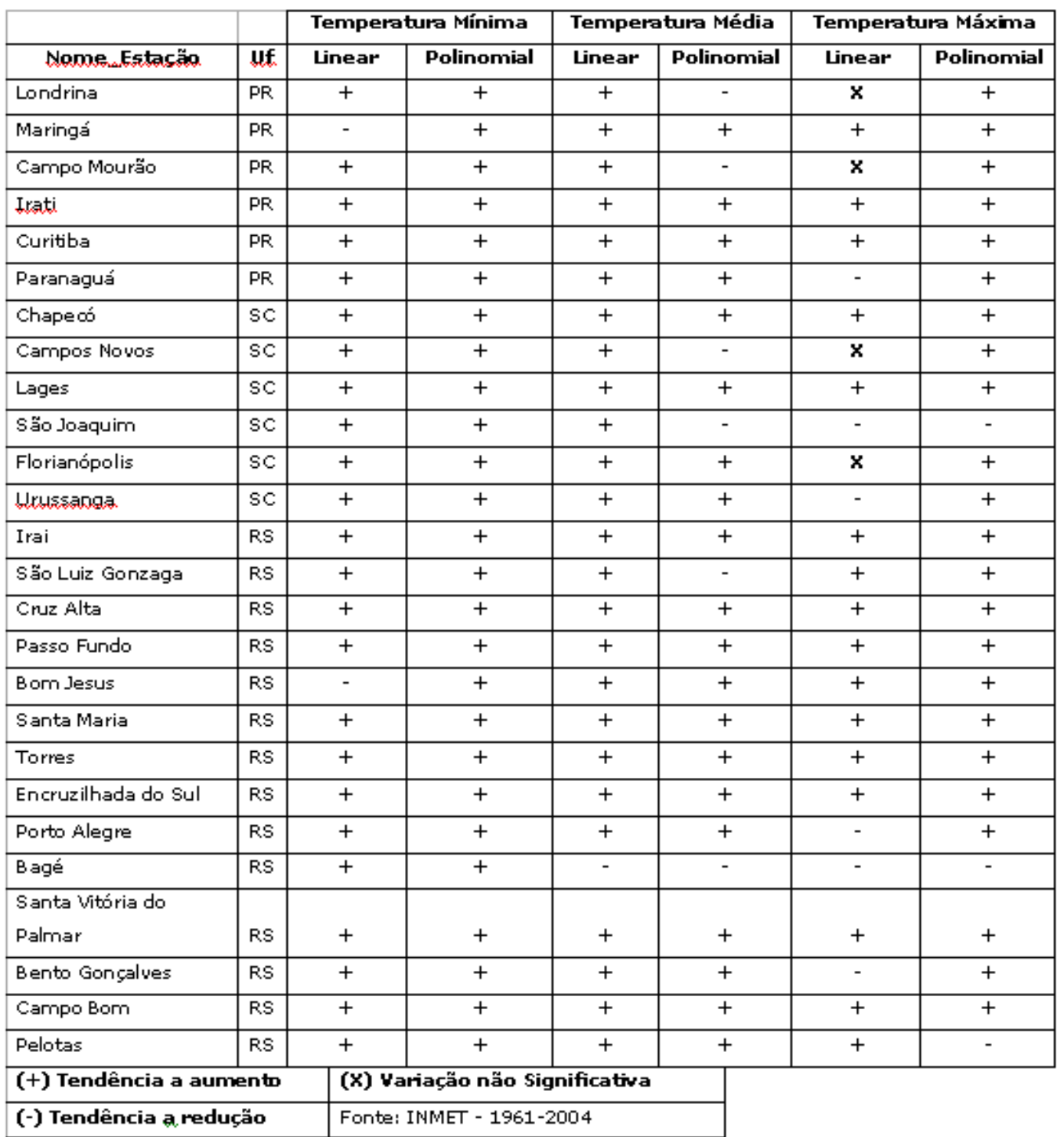

Uma analise geral dos mapas de tendências térmicas regionais revela aspectos bastante interessantes e questionáveis. Em primeiro lugar os dados registrados revelam que a intensificação do aquecimento processou-se de maneira mais explicita na porção norte da região, ou seja, no Estado do Paraná, particularmente na parte de domínio climático $\mathrm{Cfa}$; nesta o reforço das condições de tropicalidade têm se evidenciado através de invernos menos frios e chuvas mais concentradas nas últimas décadas. Mas, nem toda a região tem indicado tendência ao aquecimento, sendo que numa parte o que se destaca é a tendência ao resfriamento, como se pode notar nos indicadores da Serra Gaúcha (Rio Grande do Sul) e de algumas localidades no Estado do Paraná. Há ai, nesta tendência à redução térmica, um ponto importante para o aprofundamento das pesquisas. 


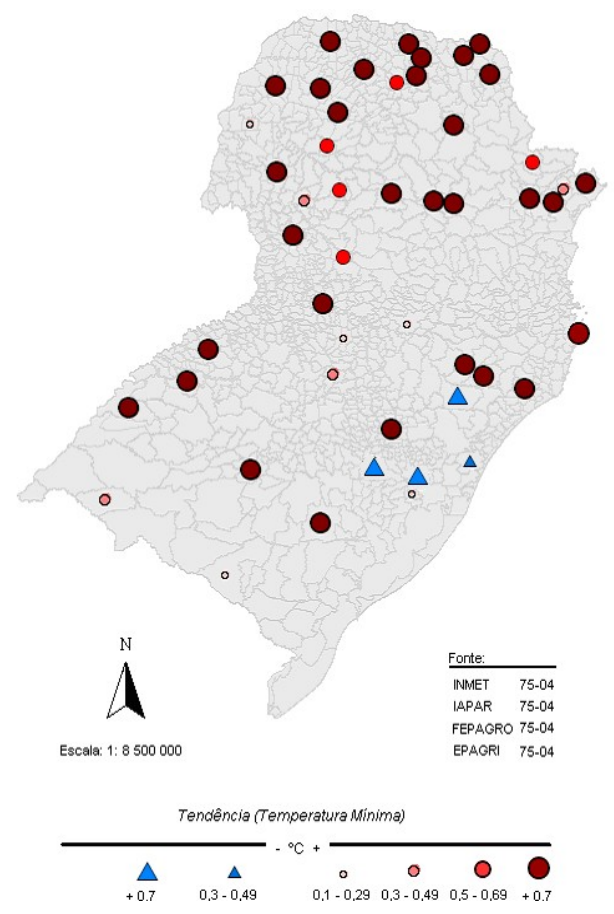

Figura 2. Tendências térmicas das temperaturas mínimas na Região Sul do Brasil.

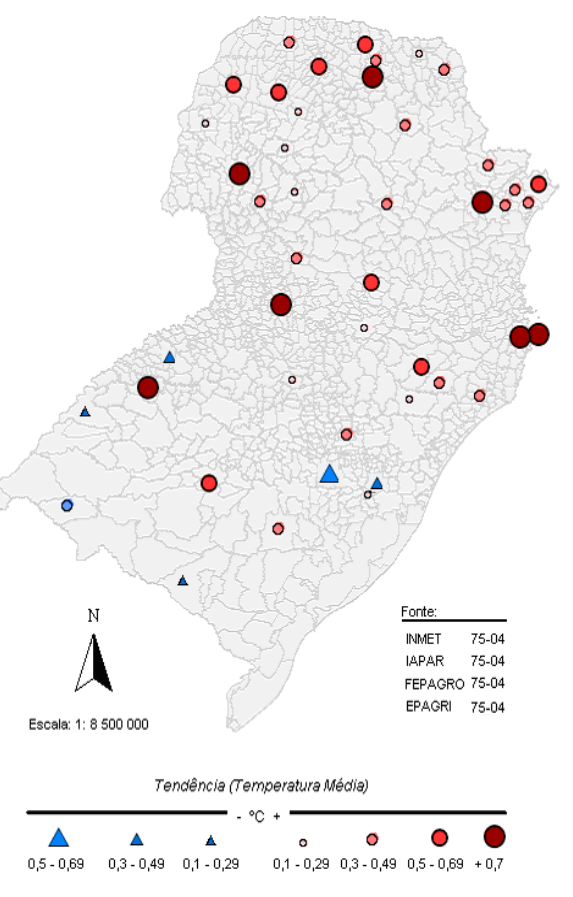

Figura 3. Tendências térmicas das temperaturas médias da Região Sul do Brasil.

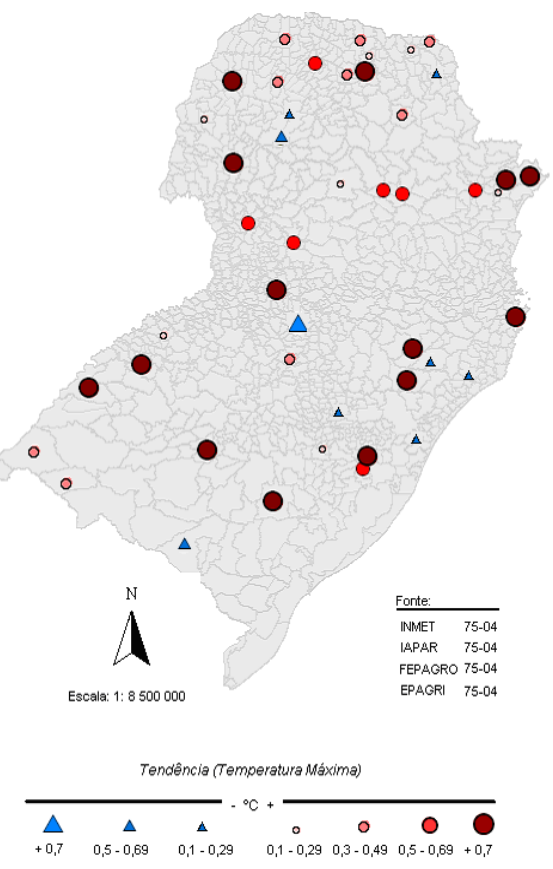

Figura 4. Tendências térmicas das temperaturas máximas da Região Sul do Brasil. 
Uma análise geral dos mapas de tendências térmicas regionais revela aspectos bastante interessantes e questionáveis. Em primeiro lugar os dados registrados revelam que a intensificação do aquecimento processou-se de maneira mais explicita na porção norte da região, ou seja, no Estado do Paraná, particularmente na parte de domínio climático $\mathrm{Cfa}$; nesta o reforço das condições de tropicalidade têm se evidenciado através de invernos menos frios e chuvas mais concentradas nas últimas décadas. Mas, nem toda a região tem indicado tendência ao aquecimento, sendo que numa parte o que se destaca é a tendência ao resfriamento, como se pode notar nos indicadores da Serra Gaúcha (Rio Grande do Sul) e de algumas localidades no Estado do Paraná. Há ai, nesta tendência à redução térmica, um ponto importante para o aprofundamento das pesquisas.

As tendências pluviométricas observadas para a região Sul do Brasil (Tabela 2) corroboram as concepções que associam a intensificação do aquecimento à elevação da umidade, ali manifestada no incremento da pluviosidade. As alterações no regime e no total das chuvas não são muito expressivas, elas se manifestam principalmente na concentração da queda d'água da atmosfera em eventos pluviais da vez mais extremos, ou seja, a elevação nos totais pluviométricos não significa nem uma melhor distribuição sazonal nem espacial das chuvas no âmbito regional.

Neste contexto a pluviosidade concentrada apresenta ainda maiores desafios ao equilíbrio ambiental regional, pois, quanto mais concentrados os episódios pluviais - mais intensos e mais rápidos, tanto mais rápidos e concentrados também se desenvolvem os processos erosivos. Considerando que parte representativa do oeste-noroeste do Paraná e do sul-sudoeste do Rio Grande do Sul já apresentam severos problemas relacionados a processos erosivos, imagina-se que, com as alterações climáticas observadas e suas tendências, os mesmos venham a se agravar. Esta concentração revela-se impactante também no processo de cheias, enchentes e inundações que colocam em situação de risco e vulnerabilidade um contingente cada vez maior da população regional.

A umidade relativa do ar também tem apresentado tendência à elevação, embora de maneira diferenciada da pluviosidade (tabela 2). Enquanto esta manifesta tendência a aumento em quase todo o quadro regional, a umidade do ar apresenta tendência variada na região; algumas localidades evidenciam nítido aumento, enquanto noutras a redução é representativa. Tanto as chuvas quanto a umidade do ar apresentaram as principais tendências à elevação quando tratadas sob a perspectiva da estatística linear, sendo que foram menos expressivas na perspectiva polinomial; esta última resultou em redução da pluviosidade e da umidade relativa no final do período analisado.

Considerando-se o tratamento estatístico efetuado sobre os dados levantados para a pesquisa, e considerando-se também o contexto dos três Estados da região Sul do Brasil, observou-se que as principais alterações detectadas nos últimos quarenta anos são mais evidentes na porção norte regional. Ou seja, as mais evidentes tendências de intensificação do aquecimento e da pluviosidade-umidade regional são mais evidentes no Estado do Paraná e menores nos outros dois, em Santa Catarina e no Rio Grande do Sul respectivamente. 
Tabela 2. Tendência pluviométrica e higrométrica para a Região Sul do Brasil

\begin{tabular}{|c|c|c|c|c|c|}
\hline I & & \multicolumn{2}{|c|}{ Precipitação } & \multicolumn{2}{|c|}{ Umidade Relativa } \\
\hline Nome_estaçãa & UF & Linear & Polinomial & Linear & Polinomial \\
\hline Londrina & $\mathrm{PR}$ & - & - & + & + \\
\hline Maringá & $\mathrm{PR}$ & $x$ & + & $\mathbf{x}$ & - \\
\hline Campo Mourão & $\mathrm{PR}$ & + & - & + & + \\
\hline Irati & $\mathrm{PR}$ & + & + & + & - \\
\hline Curitiba & $\mathrm{PR}$ & + & + & + & + \\
\hline Paranaguá & $\mathrm{PR}$ & + & + & + & + \\
\hline Chapeó & $\mathrm{SC}$ & + & - & - & + \\
\hline Campos Novos & $\mathrm{SC}$ & + & + & - & - \\
\hline Lages & $\mathrm{SC}$ & + & - & - & + \\
\hline São Joaquim & $\mathrm{SC}$ & + & + & + & + \\
\hline Florianópolis & $\mathrm{SC}$ & + & + & - & - \\
\hline Uxussanga. & $\mathrm{SC}$ & $x$ & + & + & - \\
\hline Irai & RS & + & + & - & + \\
\hline São Luiz Gonzaga & RS & + & - & - & + \\
\hline Cruz Alta & RS & - & + & - & - \\
\hline Passo Fundo & RS & + & + & + & + \\
\hline Bom Jesus & RS & - & + & - & - \\
\hline Santa Maria & RS & + & + & + & + \\
\hline Torres & RS & + & + & + & + \\
\hline Encruzilhada do Sul & RS & + & + & + & + \\
\hline Porto Alegre & RS & + & + & + & + \\
\hline Bagé & RS & + & + & + & + \\
\hline Santa Vitória do Palmar & RS & + & + & + & + \\
\hline Bento Gongalves & RS & + & - & - & + \\
\hline Campo Bom & RS & $\mathbf{x}$ & - & + & + \\
\hline Pelotas & RS & + & + & + & + \\
\hline \multicolumn{2}{|c|}{ (+) Tendência a aumento } & \multicolumn{2}{|c|}{ (x) Variação não Significativa } & & \\
\hline \multicolumn{2}{|c|}{ (-) Tendência a redução } & \multicolumn{2}{|c|}{ Fonte: INMET - 1961-2004 } & & \\
\hline
\end{tabular}

\section{Sintetizando a abordagem}

As mudanças climáticas globais e sua manifestação mais preocupante - a intensificação do aquecimento da baixa atmosfera do planeta, apontam tanto para alterações negativas quanto positivas das paisagens e das condições de vida dos homens na superfície do planeta. As alterações negativas constituem-se nas mais importantes, pois que suas repercussões acenam para o desencadeamento de conflitos gerais pela acessibilidade a determinados recursos naturais (solos, florestas, água potável, etc.) e, de maneira muito específica para a expansão geográfica e para a intensificação de determinadas enfermidades; dentre estas se destacam as metaxênicas, parasitárias e infecciosas cuja incidência depende diretamente das condições climáticas.

A intensificação do aquecimento global encontra-se, todavia, envolta 
em consideráveis incertezas e especulações, sobretudo quando se discute as causas do mesmo. A tese do resfriamento, ainda que em dimensão mínima, como seqüencial a um período de décadas sucessivas de aquecimento não está totalmente descartada, aspecto que reforça o cenário especulativo acerca da evolução da atmosfera terrestre no século que se inicia.

Num tal contexto a precaução parece ser a atitude mais correta a ser tomada pela sociedade; para tanto várias iniciativas podem ser implementadas tais como a redução do consumismo e do desmatamento, por exemplo. A estabilidade da temperatura média da Terra, ou a redução nos níveis previstos repercutir-se-á na manutenção das condições de vida no planeta, embora os cenários previstos dão como certa, em geral, a elevação das temperaturas médias do planeta nos próximos 100 anos.

Diante das alterações climáticas já observadas a ação integrada no âmbito internacional se faz necessária, particularmente quando se consideram os cenários futuros. Para tanto várias iniciativas têm sido tomadas no âmbito de organizações inter e supranacionais visando estabelecer políticas e ações para reduzir as mudanças climáticas globais e seus efeitos. O Protocolo de Kyoto, sua assinatura por todos os paises, e os avanços observados com a realização das diversas conferencias mundiais do clima indicam medidas possíveis para minimizar os impactos negativos das referidas mudanças. Todavia, há ainda muito a ser feito para que as ações se concretizem.

No que concerne às mudanças climáticas na porção sul do Brasil a analise dos dados meteorológicos revela tendência genérica ao aquecimento e elevação da pluviosidade-umidade médias. A estatística linear aponta intensificação do aquecimento climático associado à elevação das médias pluviométricas anuais, o que corrobora a tese da intensificação do aquecimento regional como reflexo do aquecimento global. O que fica evidente na analise dos dados é que o aquecimento regional se faz evidenciar particularmente na elevação das temperaturas médias mínimas e médias compensadas; as médias das máximas apresentam pequena alteração. A analise estatística polinomial, entretanto, revelou leve tendência ao resfriamento em localidades em meados da década de 1990.

De todo modo parece ficar patente, quanto mais se analisa a realidade, que o aquecimento mais intenso ou menos intenso da troposfera se repercutirá de maneira diferenciada sobre os homens; a evidencia da desigualdade de riquezas e acessibilidades coloca claramente a maior parte dos seres humanos em situação de penúria e, portanto, de maior vulnerabilidade aos impactos das mudanças globais. A realidade mostra que é preciso agir urgentemente no sentido de frear o aquecimento planetário; ela evidencia também que isto não acontecerá enquanto a concentração da riqueza e a injustiça social permanecerem nos patamares que marcam o presente momento da humanidade. A persistirem estas disparidades os cenários negativos das mudanças globais poderão ser mais impactantes e surpreendentes do que se especula.

\section{Agradecimento}

Ao Ministério da Saúde, Ministério da Ciência e Tecnologia / CNPq, UNESCO e Fundação Araucária de Pesquisa do Paraná pelo suporte financeiro ao desenvolvimento da pesquisa (Dinâmica espacial, monitoramento e controle da 
dengue na região Sul do Brasil) que deu base à elaboração deste estudo. À equipe de pesquisa do Projeto CT/Saúde - Dengue do Laboclima / UFPR, em especial ao Felipe Vanhoni Jorge pelo tratamento estatístico e gráfico da maior parte dos dados empregados neste texto.

\section{Referências bibliográficas}

GLOBAL Equity \& Climate Change - A History of the UNFCCC Negotiations for a Global Solution. Brussels: Globe International, 1999.

\section{GHCN - Global Historical Climatology Network -} http://www.ncdc.noaa.gov/ghcn/ghen.html,

IPCC - International Panel on Climate Change. www.ipcc.ch/officialdocuments. 2004.

LEGGET, J. A Natureza da Ameaça do Efeito Estufa. In: Aquecimento Global: Relatório do Greenpeace. Tradução de Alexandre Lissovsky et alii. Rio de Janeiro: Fundação Getúlio Vargas, 1992.

MENDONÇA, Francisco. Os Geógrafos e as Mudanças Climáticas na Eco-92, ou As Implicações das Mudanças Climáticas na (Re) Organização do Espaço. In: Ecos da Rio-92, Geografia, Meio Ambiente e Desenvolvimento em questão. Vanda Claudino Sales [org.]. Fortaleza: AGB, 1992.

MENDONÇA, Francisco et al. A intensificação do efeito estufa planetário e a posição dos países no cenário internacional. RA'E GA - O espaço geográfico em analise, n. 5, ano V, Curitiba-PR, Editora da UFPR, 2001. p. 99-124.

MENDONÇA, Francisco. Aquecimento global e saúde: Uma perspectiva geográfica notas introdutórias. Revista Terra Livre, ano 19, vol.1, n. 20, jan/julho 2003, pp.205-221.

MENDONÇA, Francisco. Rechauffement global et santé: Aspects généraux et quelques particularités du Monde Tropical. Annales de I'Association Internationale de Climatologie, Vol. 1, 2004, pp. 157-175.

MENDONÇA, Francisco et al. Rechauffement climatique global et expansion geographique de la dengue dans le Sud du Bresil. Actes du XVII Colloque de I'Association Internationale de Climatologie. Caen/France, 2004. p. 209-212.

MENDONÇA, F. Clima, tropicalidade e saúde: Uma perspectiva a partir da intensificação do aquecimento global. Revista da ABClima - Associação Brasileira de Climatologia, n. 1, 2006.

MENDONÇA, Francisco e DANNI-OLIVEIRA, Inês Moresco. Climatologia - Noções básicas e climas do Brasil. São Paulo: Editora Oficina e Textos, 2007.

NOVAES, Washington. Clima- realismo versus prudência. In: O Estado de São Paulo, $15 / 9 / 2000$.

SACHS, Ignacy. Estratégias de transição para o século XXI. In: BURSZTYN, Marcel (org.). Para Pensar o Desenvolvimento Sustentável. São Paulo: Brasiliense, 1993. p. 29 a 55

WOODWELL, George. Os Efeitos do Aquecimento Global. In: LEGGET, Jeremy (org.). Aquecimento Global: Relatório do Greenpeace. Rio de Janeiro: Fundação Getúlio Vargas, 1992. 